\title{
A PRECARIZAÇÃO DO TRABALHO, O REUNI E O NOVO DESENVOLVIMENTISMO ${ }^{1}$
}

\author{
Antonia Costa Andrade ${ }^{2}$ \\ Carlos Lucena ${ }^{3}$ \\ Ilma Andrade Barleta ${ }^{4}$
}

\section{Resumo}

Este artigo ao centralizar-se nos governos FHC e Lula e a ressignificação do neodesenvolvimentismo, tomou o REUNI como referência, em termos educacionais, com o objetivo de realizar um estudo comparativo entre os referidos governos, respaldado nas mudanças no neodesenvolvimento e seus impactos na sociedade e na educação. A pesquisa foi dividida em duas partes: a primeira analisa o governo FHC e os primórdios da implantação do Plano Real. A segunda, por sua vez, debate o governo Lula, demonstrando seus pressupostos, continuidades e rupturas com o governo FHC e uma ênfase final no projeto de expansão do ensino superior público denominado REUNI. Foram pesquisadas fontes primárias manifestas em jornais da época, documentos governamentais e análise do discurso dos principais atores políticos do projeto em questão. O que demonstramos é que o governo Lula não rompeu com a lógica monetarista inerente ao governo $\mathrm{FHC}$, no qual houve expansão do ensino superior privado, manifestando projetos precarizantes do trabalho dos professores. No governo Lula, o processo de interiorização da Universidade pública manifestou a contradição do acesso a alunos no ensino superior, porém em condições também precárias para o desenvolvimento da Ciência e Tecnologia.

Palavras-chave: REUNI. Neodesenvolvimento. Trabalho docente. Precarização. Neoliberalismo.

\section{LABOUR PRECARIOUSNESS, THE MEETING ANDNEW DEVELOPMENTALISM}

\begin{abstract}
This article in be centered at the FHC's government and Lula's government and in the reframe of the "neo-desenvolvimentismo", took the REUNI as a reference, in educational terms, with the target to realize a comparative study between those governments, bound in the changes of "neodesenvolvimentismo" and its impacts in the society and the education. The research was divided in two parts: the first one analyses the FHC's government and the beginning of the Real Plain. The second one, for its time, debates the Lula's government, showing its assumptions, continuities and ruptures with the FHC's government and the final emphasis in the public superior education project of expansion named REUNI. Were surveyed primary sources manifested in the newspaper of that time, government documents and the discourse's analyses of the most important actors about the project in question. What
\end{abstract}


we demonstrate is that the government of Lula did not break with the monetarist logic inherent of the FHC's government; in witch was expansion of the private superior education, showing precarizations's projects of the professor's condition of work. In the Lula's government, the process of internalization of the public University showed the contradictions of the student's access to the superior education, however in also degraded conditions to the development of Science and Technology.

Keywords: REUNI. Neodesenvolvimentismo. Professor`s labor. Precarization. Neoliberalism.

\section{LA PRECARIZACIÓN DEL TRABAJO, EL REUNI Y EL NUEVO DESENVOLVIMENTISMO}

\section{Resumen}

Este artículo al centralizarse en los gobiernos FHC y Lula y la resignificación del neodesenvolvimentismo, tomó el REUNI como referencia, en términos educativos, con el objetivo de realizar un estudio comparativo entre los referidos gobiernos, respaldado en los cambios en el desarrollo y sus impactos en la sociedad y en la educación. La investigación fue dividida en dos partes: la primera analiza el gobierno de FHC y los primeros de la implantación del Plan Real. La segunda, a su vez, debate el gobierno de Lula, demostrando sus presupuestos, continuidades y rupturas con el gobierno de FHC y un énfasis final en el proyecto de expansión de la enseñanza superior pública denominado REUNI. Se investigaron fuentes primarias manifestadas en periódicos de la época, documentos gubernamentales y análisis del discurso de los principales actores políticos del proyecto en cuestión. Lo que demostramos es que el gobierno Lula no rompió con la lógica monetarista inherente al gobierno FHC, en el cual hubo expansión de la enseñanza superior privada, manifestando proyectos precarizantes del trabajo de los profesores. En el gobierno de Lula, el proceso de interiorización de la Universidad pública manifestó la contradicción del acceso a alumnos en la enseñanza superior, pero en condiciones también precarias para el desarrollo de la Ciencia y la Tecnología.

Palabras clave: REUNI. Neodesenvolvimento. Trabajo docente. La precariedad. El neoliberalismo.

\section{INTRODUÇÃO}

O Brasil passou por grandes mudanças por ocasião do início do governo Itamar Franco, após o impeachment de Fernando Collor, no início da década de 90, século XX. Tais manifestações foram influenciadas por um profundo processo de reestruturação em âmbito internacional voltada à manutenção das taxas cumulativas do capital, independentemente do custo social. 
O advento das ideias neoliberais ganhou fôlego a partir da crise do capitalismo manifestada no final da década de 1960, no decorrer da de 1970 e início da seguinte, do século XX. Essa mesma crise pode ser dividida em três fases específicas, mas interligadas, que redefiniram formas acumulativas e colocaram em cheque o Estado de Bem-Estar Social.

A primeira fase da crise ocorreu nos Estados Unidos, no final dos anos 1960. Este País fora central para a organização do capitalismo, após o final da segunda grande Guerra Mundial. Um amplo acordo foi construído para esse fim, denominado como Sistema de Bretton Woods, responsável pela criação do Fundo Monetário Internacional (FMI) e do Banco Mundial. Nessa forma organizativa, os EUA potencializaram a internacionalização do Dólar, como âncora para todas as outras moedas dos países capitalistas. Em outras palavras, garantiram a estabilidade do sistema, por meio da estabilidade de sua própria Economia.

Porém, a situação política e econômica nos Estados Unidos agravou-se, no final dos anos 1960, em função da Guerra do Vietnã e do crescente acúmulo do capital em poder de frações da classe dominante, que despertaram protestos sociais, dentre outros fatores. Tais aspectos enfraqueceram a posição político-governamental daquele país, no qual ocorreu um conjunto de mobilizações sociais, merecendo destaque os movimentos sindical, negro, feminista e hippie, os quais questionaram, nas ruas, a política interna e externa, trazendo à tona a exclusão social que a referida política causava.

Em resposta a esses fatores que fragilizaram sua economia, o governo estadunidense investiu em políticas sociais voltadas à garantia da legitimidade governamental. Assim, com base no valor empregado nestes investimentos, somado ao alto custo com a Guerra do Vietnã, nos anos 1970, decretou-se não haver mais condições de arcar com o Sistema de Bretton Woods.

Uma forte crise internacional acompanhou a decisão em questão. Essa crise foi acompanhada por uma recessão generalizada que se agravou, ainda mais, com os conflitos do Oriente Médio em torno do apoio estadunidense ao Estado de Israel. Esse episódio inaugurou a segunda fase da crise, manifesta no desdobramento da Guerra dos Seis Dias, no final dos anos 1960, acompanhado do primeiro choque do petróleo no início da década seguinte. $\mathrm{O}$ desdobramento deste conflito entre Israel e nações árabes foi a elevação do preço do barril do petróleo, acirrando a recessão em nível internacional.

A terceira fase da crise ocorreu em virtude do Segundo Choque do Petróleo manifesto na Guerra entre o Irã e o Iraque, entre 1980 e 1988, proporcionando nova elevação do preço do barril de petróleo, com impactos consideráveis na sociedade mundializada, em nível econômico e globalizada, em nível cultural.

As três fases da crise apresentadas são essenciais para a interpretação do advento do processo neoliberal na América Latina e, especialmente, no Brasil. A elevação contínua do preço do barril do petróleo elevou os custos do acesso à matéria-prima. Da mesma forma, a 
crise econômica internacional fortaleceu princípios monetaristas voltados à reprodução do capital em sua forma financeira. O FMI assumiu um novo papel com o processo em questão. Por um lado, em face ao empobrecimento dos países periféricos, foi o responsável em elaborar políticas e exigências para a concessão de novos empréstimos para o pagamento da dívida externa crescente. Por outro lado, entre essas exigências estava a obrigatoriedade da abertura da Economia dos países periféricos aos interesses transnacionais. Essa abertura implicou na redefinição do papel do Estado Nação, quebra de monopólios, demonização de funcionários públicos, privatização, dentre outras ações.

A década de 80 , século $\mathrm{XX}$, marcou o crescimento da miséria na periferia do capitalismo, como desdobramento da elevação contínua da dívida externa. Não obstante, o limite desse empobrecimento ocorreu em função da capacidade de continuar a pagar os juros da dívida. Esse cenário econômico e político internacional potencializou a construção de planos econômicos voltados à renegociação da dívida externa - na metade da referida década, o Plano Baker e, um pouco mais à frente, o Plano Brady, que potencializou a adoção do Neoliberalismo em toda a América Latina.

Este breve relato histórico fundamenta o debate que se seguiu no Brasil e nos vizinhos latino-americanos. O Brasil foi o último país a assinar o Plano Brady, já no ano de 1994, sob o governo Itamar Franco, capitaneado pelos então Ministros de Estado Pedro Malan e Fernando Henrique Cardoso. O Plano Brady colocou os fundamentos que levaram à criação do Plano Real no Brasil e seus sucessivos reajustes.

Nas últimas décadas, os governos FHC e Lula causaram profundas mudanças econômicas, políticas e, principalmente, educacionais. A transição entre tais governos, ocorrida no início da primeira década do século XXI, implicou na continuidade das ações inerentes ao Plano Real. As dificuldades apresentadas pelo projeto neoliberal em estabilizar as economias latino-americanas implicaram em sua própria rediscussão. A adoção do neodesenvolvimentismo, no governo Lula, produziu interpretações distintas no meio intelectual, manifestas por um lado, no entendimento da retomada dos processos desenvolvimentistas expressos por Celso Furtado e, de outro lado, na defesa das ações governamentais que apontavam a continuidade dos processos políticos implantados por FHC. Em ambos os governos houve a expansão do ensino superior - na gestão de FHC, no setor privado e, na de Lula, no público, merecendo destaque o Plano de Reestruturação e Expansão das Universidades Federais (REUNI).

Nesse contexto histórico exposto, a organização lógica do pensamento de Vaisman (2000) sobre a contemporaneidade teórico-prática marxista, remete a um duplo movimento desafiador, no processo de entendimento da história do presente. Prescindindo da lógica linear, o primeiro movimento é a apropriação dos pressupostos marxistas, como base essencial pelo método científico, para compreender a história em movimento e, em sua 
totalidade, como resultado da luta de classes. Simultaneamente, o segundo movimento exige mais do que compreender tal realidade, é preciso demudá-la.

Esses pressupostos teóricos norteiam a presente pesquisa. Tendo como referência a categoria resistência e contradição, busca-se debater e construir a crítica sobre o advento do Neoliberalismo no Brasil, expresso nos governos FHC e Lula, e sua influência no ensino superior público, por meio do REUNI. Defende-se a tese que tal Plano e seu impacto na Educação Superior aceleraram a precarização do trabalho docente e afetam as condições de aprendizagem dos alunos expressando, desta forma, uma condição subordinada de desenvolvimento da Ciência e da Tecnologia, manifesta nas transformações do trabalho em nível internacional.

Para além de várias justificativas que se possa manifestar, a presente pesquisa trouxe um motivo bastante próximo e de cunho pessoal e, sobretudo político, para se concretizar. Inicialmente, há de se destacar a preocupação com a precarização do trabalho docente verificado no Ensino Superior, nas últimas décadas. Associado a isto, indica-se também o caso específico relacionado à atuação docente da autora da Tese de Doutorado que embasa este texto, além de sua militância nos movimentos sociais, desde o início dos anos 1990, no âmbito da Universidade Federal do Amapá. Neste contexto, cabe reforçar a importância de que o pesquisador compreenda o processo e o produto de sua investigação como relacionados à sua vida, a fim de orientar sua prática e contribuir à leitura da realidade que o cerca, transformando-a.

Nesse sentido, a pesquisa realizada avaliou os impactos e as contradições do REUNI no Brasil. As fontes primárias de consulta consistiram em jornais, leis governamentais e boletins sindicais. Como forma de ampliar a coleta de informações procedeu-se à análise do discurso dos Ministros de Estado $^{5}$ dos governos em questão.

\section{O GOVERNO LULA}

A eleição de Luiz Inácio Lula da Silva à Presidência da República do Brasil representou a ruptura histórica da eleição de presidentes, por via direta e indireta, com histórico de vida vinculado às frações de classe burguesa do país. Lula, personagem central na fundação do Partido dos Trabalhadores (PT) e da Central Única dos Trabalhadores (CUT), representa para alguns, uma das maiores lideranças sindicais das décadas finais do século XX e, para outros, é um autêntico intelectual orgânico das classes trabalhadoras. Isto porque traz em seu retrospecto político, a militância e a liderança ativas junto aos metalúrgicos da área da Grande São Paulo, sobremaneira os localizados nos municípios de Santo André, São Bernardo, São Caetano e Diadema (ABCD paulista).

O lema Trabalhador vota em trabalhador cedeu lugar ao A esperança venceu o medo. A imagem do "sapo barbudo", como certa vez o ex-governador do Rio de Janeiro, 
Leonel Brizola, referiu-se a Lula, foi substituída pela de Lula conciliador, sereno, sensato e apaziguador: o Lulinha Paz e Amor. (GOMES, 2004). Porém, essa não era apenas uma estratégia para vencer as eleições. Sua concepção traduzia uma clara sinalização política, expressa pelas alianças partidárias realizadas pelo PT, que implicava na adoção de propostas governamentais voltadas à legitimação de formas monetaristas de reprodução do capital.

A análise ao pensamento crítico e revolucionário dentro do PT ganhou fomento após as sucessivas derrotas no pleito eleitoral de Lula. A articulação, corrente à qual Lula era pertencente, culpou a direção nacional do Partido, controlada por correntes críticas ao capitalismo, pelo fracasso das negociações com o Partido da Social Democracia Brasileira (PSDB) voltadas à construção de uma chapa única para concorrer às eleições do ano de 1994.

De acordo com Marques e Pereira (2005, p. 14), como desdobramento do II Congresso do PT de 1999, aprovou-se um documento denominado "[...] por uma esquerda republicana", traduzindo o fim da opção do petista pelo Socialismo.

\begin{abstract}
Ao não defendermos o socialismo, não significa que passamos a aderir ao capitalismo como modelo econômico. Propomos uma esquerda que resgate as tradições históricas das lutas democráticas e republicanas, que na sua essência, são lutas por liberdade, por igualdade, por justiça, por cidadania e por direitos. Democracia, desde suas origens gregas, além da liberdade política e do pluralismo, significa também uma sociedade de equilíbrio, social e economicamente eqüitativa, com direitos iguais perante a lei [...]. O programa do PT deve atacar essas condições estruturais do capitalismo brasileiro que concentram a riqueza e a terra e impedem a democratização do capital e da propriedade. Promover uma radical reforma democratizadora do capital, da propriedade e das rendas, e republicanizadora do Estado, tem, no Brasil, o alcance de uma revolução.
\end{abstract}

A democracia representativa passou a ser o grande destaque, justificando que a partir da conquista do governo federal seria possível iniciar um processo de transformação. Para isto, tornaram-se necessárias as alianças com partidos de centro ou centro-direita, como estratégia para obter o comando do Executivo Federal. A estratégia propagandística utilizada ia de encontro às mudanças que se desenvolviam no interior do Partido. Tanto é que a primeira ação, após a assumir a presidência, foi a divulgação de uma carta de intenções políticas à população - a carta ao povo brasileiro - cujo "povo brasileiro" era constituído na realidade pelos banqueiros, investidores e grandes cartéis internacionais.

Logo em sua posse, Lula sinalizou que as mudanças propostas pelo governo seriam lentas e graduais. Ao mesmo tempo, o governo federal produziu um forte discurso de mudança social, traduzindo, através da mídia, os pressupostos de que suas ações eram inéditas na política brasileira. Todavia, na verdade o governo Lula revitalizou o discurso evolucionista utilizado no governo de Fernando Collor, que esbravejara contra os militares e a Nova República, ao utilizar constantemente em seus discursos a expressão "nunca nesse país...", dando ênfase ao inédito, ao novo, à ruptura com o passado.

O governo federal não apregoou mudanças na política econômica, mantendo, em 
síntese, os mesmos pressupostos do governo anterior. Ao mesmo tempo, sinalizava ações em longo prazo voltadas à retomada do crescimento econômico do Brasil. Um forte discurso anti-inflacionário foi produzido durante todo o governo do presidente Lula. A derrota sobre a inflação teve inspiração filosófica de competência governamental e administrativa, especialmente nos comparativos inerentes ao governo FHC. A política econômica se norteou em uma redefinição das normas e formas de funcionamento do Banco Central, tendo como pressuposto elevar sua autonomia operacional. O governo federal justificou essa ação como único caminho possível para garantia da estabilidade econômica, condição essencial para a volta do crescimento do país.

O controle da inflação e a política monetária adotada pelo Banco Central foram justificados pela adoção de discursos expressos no desenvolvimento sustentado. Mercadante (2010) demonstra que a estratégia expressa pelo governo foi a tentativa de crescimento econômico sustentável voltado a transformar o Brasil na quinta maior economia do planeta. O país colheria vantagens econômicas se mantivesse seu crescimento econômico, ficando, segundo a opinião de Mercadante, atrás apenas do Japão, da Índia, dos Estados Unidos e da China, a qual já ocuparia, há bastante tempo, a liderança mundial.

A adoção de medidas econômicas ortodoxas fez crescer o nível de confiança do Brasil com o FMI e demais bancos privados internacionais. Houve a queda do "RiscoBrasil", elevação de entrada de capitais de curto prazo e valorização da taxa de câmbio e dos títulos da dívida externa. Um forte discurso sobre a importância e conquistas do Plano Real voltadas ao crédito, abertura da Economia, financiamento e dívida externa foi elaborado pelo "núcleo duro" do governo federal. Foram cortados gastos, mantendo as bases de uma rígida disciplina fiscal. Esse corte de gastos e ajuste fiscal, baseado no corte de investimentos, tinha como objetivo prover recursos para o pagamento de juros da dívida externa.

Em seu primeiro mandato, o governo Lula manteve os mesmos pressupostos do de FHC com referência às metas da inflação e câmbio flutuante e, no campo político, a manutenção da hegemonia das mesmas classes sociais. Apesar de manter suas alianças políticas com o movimento sindical e parcela dos movimentos sociais, adotou políticas econômicas voltadas ao conservadorismo liberal, atendendo ao setor parasitário do mercado financeiro.

Algumas questões se colocaram ao PT, especialmente no que se refere aos partidos de posição histórico-crítica contra o capitalismo. As justificativas políticas do PT quanto às suas ações econômicas, perante a sociedade, partiram do pressuposto de que:

[para] governar o capitalismo melhor e com mais justiça do que uma coalizão de direita, uma coalizão de esquerda precisa reconhecer a lei básica do capitalismo: a taxa de lucro dos empresários, dos capitalistas ativos, deve ser mantida em nível satisfatório para que eles continuem a investir. Conforme observou Przeworski, os empresários têm o 'poder de veto' sobre o sistema. Se deixam de investir, o crescimento econômico estanca e o país entra em crise. Por isso, algum tipo de 
associação com os empresários produtivos é essencial. (BRESSER-PEREIRA, 2005, p. 15).

Em sociedades marcadas por uma história política movida pelo autoritarismo, a ausência de democracia e participação popular proporciona fundamentos para que os governos, assim que eleitos, busquem legitimidade política junto à sociedade civil, aproximando-se dos valores hegemônicos conservadores inerentes às classes dominantes nacionais e internacionais.

Isto porque, eleito o novo governo, a sociedade civil tenderá a dar um voto de confiança aos novos governantes. Entretanto, a sociedade civil, e principalmente seus componentes mais à direita, esperam que o novo governo, ainda que conservando uma retórica de esquerda, revele rapidamente seu respeito pela propriedade e pelos contratos - pela ordem estabelecida, portanto - e que não adote políticas redistributivas fortes. Caso contrário, o governo correrá o risco de perder seu apoio. (BRESSER-PEREIRA, 2005, p. 18).

O primeiro mandato de Lula teve a seu favor uma conjuntura internacional materializada pelo crescimento econômico mundial referente ao Produto Interno Bruto (PIB), proporcionando moderado crescimento econômico no Brasil. Isso proporcionou que o governo repassasse fundos ao capital financeiro internacional, mantendo intactas as premissas filosóficas e políticas do projeto neoliberal.

As políticas assistencialistas, em que pese sua eficiência na redução de tensões sociais, tiveram um efeito paliativo com referência à pobreza, pois não proporcionam condições efetivas para a sua superação, mantendo intocadas as suas bases constitutivas. Por outro lado, sua política social não revelou inovações. $O$ único gasto social a aumentar foi o assistencialista, através da substituição da Bolsa-Escola, que exigia dos pais pobres que os filhos estivessem na Escola, para a Bolsa-Família, ou seja, ao invés de ênfase em políticas universalistas, que são de esquerda, adotou uma política conservadora de focalização.

Um considerável número de dirigentes sindicais passou a constituir os quadros políticos do Estado Brasileiro, esvaziando, sobre medida, os sindicatos "cutistas" no país. Da mesma forma, ocorreu a redução do número de greves, especialmente nas categorias mais organizadas, em virtude do esvaziamento das lutas impostas por esses dirigentes que, apesar de ocupar os referidos cargos, ainda mantiveram controle político dos sindicatos.

A eleição de Lula demonstrou que o PT adotou um conjunto de medidas as quais criticou em toda a sua história. Suas relações com bancos privados e demais segmentos vinculados à reprodução do capital relacionados à cooptação de dirigentes sindicais colocou esse governo em pressupostos similares ao governo FHC. Andrioli e Schmalz (2006) destacaram as principais ações do governo Lula que o aproximaram do governo FHC, dando ênfase na política macroeconômica, na prioridade no pagamento da dívida externa, no controle da inflação e no corte dos gastos públicos, bem como na implementação de um 
conjunto de reformas manifestas na Previdência Social, na área tributária, privatização, Lei de falências, liberação de transgênicos e reforma trabalhista.

\section{O NOVO DESENVOLVIMENTISMO}

O governo Lula adotou teses econômicas denominadas como Novo Desenvolvimentismo. Essas teses baseiam-se na defesa de um Estado Liberal-Social como pressuposto para a consolidação de políticas econômicas e sociais voltadas a esta forma de desenvolvimento. Constata-se que o mesmo encantamento de FHC pelo Liberalismo Social se reproduziu, e teve continuidade, no governo Lula. A ênfase de FHC em demonstrar que seu governo não era neoliberal ganhou força no governo Lula.

O conceito de Novo Desenvolvimentismo apresenta algumas características que o diferem do projeto neoliberal, dentre as quais se destaca que:

[...] rejeita a estratégia de crescimento com poupança estrangeira e a liberalização da conta de capitais. Além disso, propõe que a taxa de câmbio seja administrada e acredita que é necessária uma estratégia para superar as altas taxas de juros/valorização da moeda, que mantém a economia brasileira instável. (BRESSER-PEREIRA, 2006, p. 6).

Essa concepção entende que a Nação tem condições de fortalecer a democracia formulando um projeto de desenvolvimento nacional coordenado pelo mercado. Isso implica em uma ação governamental volvida à construção de um novo pacto social voltado ao desenvolvimento econômico, cuja base é a potencialização dos empresários para concorrer no mercado internacional.

Estava em jogo, segundo a concepção governamental, a formulação de um conjunto de propostas econômicas nacionais direcionadas à construção de estratégias políticas que aproximem o Brasil e os demais países da América Latina, aos países centrais, oferecendo fundamentos e proposições reais para que tais países concorram no mercado em condições favoráveis. No governo FHC, essa afirmação implicava na busca incessante da liderança brasileira sobre os demais países latino-americanos.

Para o Novo Desenvolvimentismo, a partir do fracasso do Neoliberalismo como alternativa de ajuste econômico, a globalização da cultura e a mundialização da Economia constituem-se em possibilidades para a manifestação de uma intensa competição no mercado. Isso implica no fortalecimento do Estado Nacional em nível fiscal, administrativo e político, elaborando condições reais, para que as empresas nacionais possam concorrer em âmbito internacional. Para isso era necessária a centralidade do governo federal em termos de gestão de políticas econômicas nacionais voltadas a esse fim.

O Estado deve atuar apenas na formulação de políticas nacionais, na definição das instituições responsáveis pela organização da sociedade e promover a segurança da 
população, utilizando para tal, recursos humanos de alto nível intelectual existentes na sociedade. Para Bresser-Pereira (2008, p. 399) o Estado e sua administração não devem se voltar para a obtenção de lucros econômicos, seu aspecto gerencial deve se voltar ao atendimento do "[...] 'cliente-cidadão' e dois de seus três mecanismos específicos de responsabilização - administração por objetivos e competição administrada visando à excelência - foram emprestados da administração de empresas. Isso não deve ser mal interpretado."

A reforma gerencial, entendida por Bresser-Pereira em termos do modelo estrutural de gerência pública, destina-se essencialmente a aumentar a capacidade do Estado de garantir direitos sociais e republicanos, sem incorrer nas deficiências que caracterizaram o Estado do Bem-Estar Social burocrático do século XX. Seu pressuposto de atuação parte do princípio de não realizar uma abertura da Economia de forma indiscriminada, negociando esta mesma abertura através de acordos regionais e internacionais, não renunciando, ao mesmo tempo, à implementação e à gestão de políticas industriais.

Dentre as diferenças características do Novo Desenvolvimentismo e do Neoliberalismo, merece destaque a atuação do Estado-Nação. Assim, conforme o primeiro conceito, o Estado deve elaborar uma poupança financeira forçada, investindo apenas em setores estratégicos da Economia, acreditando, ao mesmo tempo, na potencialidade do setor privado em investir no crescimento da Economia nacional.

O ponto de partida para tal é o fortalecimento do Estado, visando suprir as carências de uma sociedade movida pela lógica do mercado, que se mostrou ineficaz para regular as trocas capitalistas. Utilizam-se das políticas industriais moderadamente, apoiando apenas empresas em condições de competir internacionalmente - o que está em jogo não é o protecionismo industrial, mas estratégias que capacitem as indústrias nacionais à competição.

De acordo com Bresser-Pereira (2008), o desenvolvimento de um país, em consonância às forças do mercado, deve apresentar os seguintes elementos: estabilidade macroeconômica; Estado forte e políticas econômicas voltadas ao desenvolvimento; promoção de poupança interna; e incentivo à inovação empresarial. Em contraposição à postura política dos países dominantes, de pensamento neoliberal, que defendem a transferência de recursos econômicos para os países em desenvolvimento, o Novo Desenvolvimentismo parte do pressuposto que tais países não necessitam desta ajuda para se desenvolver.

Os pressupostos neoliberais entendem que o endividamento externo é relacionado e inerente às economias dos países em desenvolvimento. Ao mesmo tempo, a estabilidade macroeconômica se baseia nos seguintes pressupostos: controle pelo governo, do déficit público e de suas despesas, mantendo uma poupança que viabilize seus investimentos; ampliação do mandato do Banco Central, controle da inflação e equilíbrio da balança de 
pagamentos; competitividade da taxa de câmbio; e redução da taxa de juros relacionados à estabilidade dos preços.

O Novo Desenvolvimentismo visa ao controle total de todas as contas da Nação. Trata-se de conta corrente, da redução do endividamento do Estado e da formação de contas externas, visando manter a autonomia nacional. O propósito dessa concepção de desenvolvimento é administrar a taxa de juros da Economia, mantendo como proposta de ação o câmbio flutuante.

As ações expressas pelo Novo Desenvolvimentismo causaram impacto em políticas educacionais criadas para esse fim, merecendo destaque o ensino superior. A expansão da universidade pública no Brasil foi um processo contraditório que materializou a inclusão educacional com a precarização das condições de ensino oferecidas.

\section{O GOVERNO LULA E O REUNI}

A reforma universitária expressa no Governo Lula manifesto pelo REUNI, por meio do Decreto Presidencial n. 6.096, de 24 de abril de 2007 (BRASIL/Presidência da República, 2007), materializou mudanças nessa modalidade de ensino baseadas na ocupação de possíveis vagas ociosas, currículos flexíveis, implantação de formas de mobilidade acadêmica interinstitucional, crescimento da oferta de cursos de graduação e expansão da Educação a Distância (EaD), Lima (2009, p. 1-2) analisa a materialização da reformulação no país, ganhando racionalidade nos governos:

A reformulação da Educação Superior que está sendo realizada pelo governo Lula da Silva encontra-se inserida em um amplo reordenamento do Estado brasileiro, caracterizado pela sistemática diluição das fronteiras entre público e privado, a partir da materialização da noção de público não estatal, operada pelas parcerias público-privado.

Em conformidade à análise de Lima (2009), Silva Jr. e Sguissard (1999) entendem que tal processo permeou o governo FHC, ocasião em que a educação passou a ser inserida no rol de ações não exclusivas do Estado. Por seu turno, outros autores concebem que o governo Lula aprofundou o processo de reordenamento do Estado brasileiro, por intermédio de mais uma etapa da reforma da Educação Superior. (NEVES, 2004; NEVES, SIQUEIRA, 2006; LIMA, 2007).

A compreensão da educação sem suas características de "bem público" institui os alicerces políticos e jurídicos para a redução das fronteiras entre público e privado: se a educação é um "bem público" e instituições públicas e privadas prestam esse serviço público (não-estatal), está justificado, por um lado, o financiamento público para as instituições privadas e a ampliação da isenção fiscal para estas instituições, e, por outro, também a 
Artigo

doi: $10.20396 /$ rho.v18i1.8645868

destinação de verbas do setor privado para as atividades de ensino, pesquisa e extensão das instituições públicas. (LIMA, 2009).

O que se percebe é a continuação de uma racionalidade exposta no governo Itamar Franco voltada ao privilégio da rede privada de ensino e à privatização interna das instituições públicas. A isenção fiscal foi criada pelo Fundo de Financiamento ao Estudante do Ensino Superior (FIES) e o pelo Programa Universidade para Todos (ProUni). A política do MEC para o ensino superior brasileiro, no governo Fernando Henrique Cardoso, beneficiou-se das medidas adotadas nas gestões anteriores, sobretudo no que se refere à extinção do Conselho Federal de Educação, ocorrida no Governo Itamar Franco. A partir de então, o MEC depositou maior responsabilidade para o ensino superior ao setor privado, demonstrada pela crescente e vultosa participação dessa esfera na oferta de vagas.

No interior das Instituições Federais de Ensino Superior (IFES), o Plano de Desenvolvimento Institucional (PDI) e a política de avaliação implementada pelo Sistema Nacional de Avaliação da Educação Superior (SINAES) conservam a consistência meritocrática e produtivista que norteou a política de avaliação da administração de Cardoso, naturalizando a privatização no interior da educação superior, pela diversificação das suas fontes de financiamento alcançada por meio da constituição de "receitas próprias" geradas com a venda de "serviços educacionais", através das fundações de direito privado. (MELO, 2006).

O REUNI foi influenciado por programas nacionais e internacionais voltados à reformulação da educação manifesta por interesses conservadores. Em âmbito nacional, sofreu influência do Programa "Universidade Nova", proposto pela Universidade Federal da Bahia (UFB), voltado à organização de bacharelados interdisciplinares e formação profissionalizante. A diferença entre o REUNI e o Programa adotado pela UFB ficou explícita em termos quantitativos voltados ao financiamento. Em outras palavras, o primeiro previa maiores volumes de financiamento público, enquanto o segundo foi implantado com baixo volume de recursos.

Em âmbito internacional, o REUNI recebeu influência do Banco Mundial - e seus ditames voltados aos países periféricos subordinados em termos da divisão internacional do trabalho - e do Processo de Bolonha. Constata-se que sua fundamentação possui como código teórico e político a reforma da Educação Superior europeia, denominada "processo de Bolonha", que tem seu início em 1999 e persiste no início do novo século, com o desígnio de edificar um espaço europeu de Educação Superior até o ano 2010, por meio da outorga de um sistema de grau comparável, abalizado, fundamentalmente, em ciclos e da promoção da mobilidade de estudantes. Registram-se resistências a este processo, pela fragmentação da formação profissional que desenvolve e pelo indicativo de formação de um promissor "[...] mercado educacional [...]" europeu, facilitando a atuação das empresas educacionais. (ROSA, 2003). 


\section{Revista HIIST'TEIDBR On-line}

O processo de reestruturação do ensino público brasileiro é marcado pelos pressupostos do governo FHC manifestos na limitação orçamentária e subordinação das IFES ao Ministério do Planejamento, Orçamento e Gestão (MPOG). Em 2006, uma forte propaganda governamental contra a "ineficiência" das universidades públicas e a necessidade de construção de uma "universidade nova" ganhou coro no Brasil.

A limitação de recursos para o projeto de expansão marcou o processo então em curso. $\mathrm{O}$ que se percebe no referido projeto é que o oferecimento de recursos econômicos às universidades públicas implicaria no cumprimento de metas em prazos estabelecidos. Verifica-se a adoção de um plano de metas oriundos das empresas, baseado em critérios empresariais de produtividade como condição para a disputa de recursos entre as diferentes IFES.

Algumas questões merecem destaque na análise do REUNI. O princípio da indissociabilidade entre ensino, pesquisa e extensão é esquecido no processo em questão. $\mathrm{O}$ que nos chama a atenção é a redefinição do próprio conceito de autonomia universitária proposto no projeto. Na prática, os limites dessa "autonomia" são voltados ao atendimento dos ativos governamentais e seus pressupostos competitivos influenciados pela lógica mercadológica expressa pelas forças do mercado. A sua preocupação com as taxas de evasão no ensino superior é acompanhada pela utilização de pressupostos voltados ao interesse da formação profissional pela lógica do mercado. A flexibilidade profissional inerente à influência toyotista na organização da produção capitalista está presente. A amplitude formativa, cujos limites ocorrem na lógica alienada e estranhada do trabalho, atende aos interesses reprodutivos do capital em comprar uma força de trabalho dócil e adaptável ao processo produtivo.

Esse entendimento na relação entre trabalho e capital fortalece a crítica ao sentido da educação nas mudanças, no mundo do trabalho. Na prática, os quatro posicionamentos valorativos podem ser assim elucidados:

\footnotetext{
[...] aprender a aprender [...]: o primeiro posicionamento considera mais desejável o processo de aprendizagem que o indivíduo realiza sozinho, pois somente dessa forma se produziria a sua autonomia; o segundo ressalta que a metodologia desse processo deve ser desenvolvida pelo próprio indivíduo; o terceiro aspecto é o que considera primordial na condução do processo de aprendizagem, as necessidades e interesses do aluno, acentuando o aspecto funcional da educação e, por fim, o quarto posicionamento valorativo traz a ênfase para uma educação que esteja em sintonia com a sociedade do conhecimento. "Aprender a aprender é, pois, [...] um lema que sintetiza uma concepção educacional voltada para a formação, nos indivíduos, da disposição para a constante e infatigável adaptação à sociedade regida pelo capital. (DUARTE, 2003, p. 11, grifo do autor).
}

Com base na lógica toyotista expressa anteriormente, percebemos que a educação expressa no REUNI atende aos princípios de potencializar a exploração máxima da força de trabalho, tanto em nível da mais-valia absoluta, como relativa. A lógica reprodutiva proposta 


\title{
Revista HIISTEYIDIR On-line
}

Artigo

doi: $10.20396 /$ rho.v18i1.8645868

nesta forma de ensino implica na intensificação do trabalho dos professores, elevando de forma considerável e, em muitos casos, sem condições estruturais para esse fim, a relação entre professores e alunos nas salas de aula, privilegiando formas educativas manifestas em princípios tradicionais. Em outras palavras, o que se espera dos professores é uma fórmula de ensino baseada na simples transmissão de conteúdos e adoção de formas avaliativas para esse fim, voltadas à reprodução de um conhecimento pronto e acabado.

O entendimento desta concepção educacional, em que pese seu apelo do "novo e inclusivo" recupera os princípios positivistas presentes na obra de Émile Durkheim, especialmente no que se refere ao papel do Estado como legitimador da harmonia e da disciplina. O Estado tem importante papel na educação, sendo que tudo o que é educação deve ser submetido à sua influência. Porém, isto não quer dizer que o Estado deva monopolizar o ensino: ao fato de deixar abrir escolas que não sejam as suas, não se segue o fato de que deva tornar-se estranho ao que nelas venha a passar, de maneira que a educação privada deve estar sob seu juízo e fiscalização:

\begin{abstract}
Para Durkheim é preciso construir uma harmonia para o trabalho. A educação é em essência, um fenômeno social que consiste em socializar os indivíduos. A educação assegura a diversidade, permitindo especializações. Com a especialização do trabalho provoca um primeiro fundo de idéias e de sentimentos comuns, mais rica diversidade de aptidões profissionais. Com efeito, a educação é para a sociedade o meio pela qual ela prepara as condições essenciais da própria existência. [...] A educação consiste em habituar os indivíduos a uma disciplina, a qual deve ter, e não pode deixar de ter, um caráter autoritário. Formar os indivíduos, tendo em vista a integração na sociedade, é torná-los conscientes das normas que devem orientar a conduta de cada um e do valor imanente e transcendente das coletividades que cada um pertence ou deverá pertencer. A educação visa criar no homem um ser novo. (LUCENA, 2013).
\end{abstract}

O princípio positivista relacionado à construção de uma lógica do trabalho alienado é "camuflado" por meio do "canto da sereia" da inclusão social manifesta pelo governo federal, podendo ser identificado nas propostas da ampliação de entrada de classes populares à universidade pública, na supressão do vestibular, na formação extensa, no aumento dos índices de aprovação, dentre outros aspectos sedutores; assim, ganham adesões de muitos desavisados, mesmo porque essas mesmas metas já foram móveis de lutas por parte dos defensores da universidade pública. No entanto, as condições de oferta desse programa, como se discutiu anteriormente, sem o suficiente aporte de recursos, favoreceram tão somente a precarização da instituição e um ensino de "qualidade" duvidosa.

Os documentos encobrem o sentido das mudanças que estão sendo impostas ao ensino superior no Brasil, pois sob propaganda de que se abre a universidade aos pobres, se estará oferecendo um engodo a essa mesma população, conforme publicação do Sindicato Nacional dos Docentes da Educação Superior (ANDES-SN, 2007, p. 19), que adverte: “[...] o governo, por meio do PDE, busca implantar, para a maioria desfavorecida da população, 
uma pseudo-educação de nível superior, que poderia ser caracterizada como um pós-médio ou ensino compensatório decorrente da baixa qualidade da educação básica."

Por fim, deve-se destacar que a proposta busca, pelos seus diagnósticos e propostas concretas, particularmente a dos bacharelados interdisciplinares, ser uma referência compatível com outros projetos relativos a esse nível de ensino, como é o caso daquele surgido nos países da União Européia, no âmbito do Processo de Bolonha e, também, do que "Sguissardi (2008, grifos do autor) denomina de 'Modelo da Universidade Mundial do Banco Mundial' [numa alusão a Hugo Aboites que cunhou esta expressão, em 1996] ou de Modelo Anglo-Saxônico de Universidade." (LÉDA; MANCEBO, 2009, p. 58).

O trabalho dos professores é atingido com as mudanças propostas no REUNI. Um intenso processo de precarização das condições e exercício do trabalho é imposto a esses profissionais, atendendo aos trâmites do capitalismo, que aposta na intensificação do trabalho e absorção do tempo livre dos trabalhadores. O que se percebe é a instauração de um trabalho precarizado, acompanhado de condições também precarizadas de formação educativa.

Encontramos na obra de Marx a teorização para o processo aqui apresentado. Guardadas as especificidades históricas do período em questão, Marx (1988, p. 25, grifo do autor) demonstrou a condição miserável da educação oferecida aos trabalhadores na Inglaterra do século XIX.

Ao visitar uma dessas escolas expedidoras de certificados fiquei tão chocado com a ignorância do mestre-escola que lhe disse: "Por favor, o senhor sabe ler? Sua resposta foi: Ah! Algo (summat). E, como justificativa, acrescentou: De todos os modos estou à frente dos meus alunos" [...] A primeira escola que visitamos era mantida por uma Mrs. Ann Killin. Quando lhe pedi para soletrar o sobrenome, ela logo cometeu um erro ao começar com a letra C, mas, corrigindo-se imediatamente, disse que seu sobrenome começava com K. Olhando sua assinatura nos livros de assentamento escolares, reparei, no entanto, que ela o escrevia de vários modos, enquanto sua letra não deixava nenhuma dúvida quanto a sua incapacidade de lecionar. Ela mesma também reconheceu que não sabia manter o registro [...] Numa segunda escola, encontrei uma sala de aula de 15 pés de comprimento e 10 pés de largura e nesse espaço contei 75 crianças que estavam grunhindo algo ininteligível. Não é, porém, apenas nessas covas lamentáveis que as crianças recebem certificados escolares, mas nenhuma instrução, pois, em muitas escolas onde o professor é competente, os esforços dele são de pouca valia, em face ao amontoado atordoante de crianças de todas as idades, a partir de 3 anos. Sua receita, mísera no melhor dos casos, depende totalmente do número de pence, recebidos do maior número possível de crianças que seja possível empilhar num quarto. A isso acresce o parco mobiliário escolar, carência de livros e outros materiais didáticos, bem como o efeito deprimente, sobre as pobres crianças, de uma atmosfera fechada e fétida. Estive em muitas dessas escolas, onde vi séries inteiras de crianças não fazendo absolutamente nada; e isso é certificado como freqüência escolar e, na estatística oficial, tais crianças figuram como sendo educadas (educated). 
Marx (1988, p. 26) prossegue retratando a educação oferecida aos trabalhadores nas indústrias metalúrgicas de estamparia inglesa. $\mathrm{O}$ autor demonstra que, em uma sociedade de classes organizada nas fronteiras da reificação crescente, o acesso ao conhecimento é heterogêneo e diversificado:

Toda criança, antes de ser empregada numa dessas estamparias, deve ter frequientado a escola ao menos por 30 dias e por não menos de 150 horas durante 6 meses que precedem imediatamente o primeiro dia de seu emprego. Durante a continuidade de seu emprego na estamparia, precisa igualmente freqüentar a escola por um período de 30 dias e de 150 horas a cada período semestral. [...]. Em circunstâncias normais, as crianças frequientam a escola de manhã e à tarde por 30 dias, 5 horas por dia e, após o decurso dos 30 dias, quando estatutária global de 150 horas foi atingida, quando eles, para usar seu linguajar, acabaram o seu livro, voltam para a estamparia, onde ficam de novo 6 meses até que vença outro prazo de freqüência escolar, e então ficam novamente na escola até que acabem o livro novamente. [...]. Muitos jovens que freqüentavam a escola durante as 150 horas requeridas, quando voltam ao término de 6 meses de permanência, estão no mesmo ponto em que estavam no começo. [...]. Eles naturalmente perderam tudo quanto tinham adquirido com sua freqüência anterior à escola.

As afirmações de Marx demonstram que a precariedade educativa dos filhos dos trabalhadores não é algo inédito no modo de produção capitalista. Atualmente, em que pesem os discursos do "canto da sereia" em termos da elevação da sabedoria e inclusão social, o que se verifica é a permanência de um processo formativo centrado nas fronteiras do trabalho alienado e estranhado, cujo conteúdo empobrece o próprio trabalhador desprovido dos meios de produção.

Marx debateu a questão entre o trabalho e o capital na sociedade capitalista, afirmando em seus Manuscritos que nem os deuses, nem a Natureza, mas só o homem, pode ter esse poder estranho sobre os próprios homens. Com a culminação do processo de reificação, a circulação acaba por apagar a diferença entre as mercadorias, por igualar os intercambiantes e o dinheiro apresenta-se como uma matéria geral de todos os contratos e, com isso, apagam-se as diferenças. Uns enriquecem, outros empobrecem, uns acumulam valores de uso, outros valores de troca, uns obtêm mercadorias cujo valor desaparece no consumo e outros, força de trabalho cujo consumo produz valor.

Com o desenvolvimento da sociedade moderna instaura-se a separação entre o trabalho manual e o intelectual, entre instrução profissional e instrução geral. $\mathrm{Na}$ sociedade capitalista que generaliza as exigências do conhecimento sistematizado existe uma contradição. Por ser esta sociedade baseada na propriedade privada dos meios de produção, os recursos produtivos provenientes do trabalho dos homens são adquiridos pela parcela da sociedade detentora dos meios de produção. A Ciência é incorporada ao trabalho produtivo, transformando-se em potencial material atuando no capitalismo como um meio de produzir riqueza. $\mathrm{O}$ capital não a criou, mas desenvolveu formas de explorá-la, transformando-a numa mercadoria adequada ao seu interesse. Uma mercadoria que é utilizada, a princípio, como um meio de separação entre o saber e o trabalhador e, posteriormente, através da 


\title{
Revista HIIST'TEIDBR On-line
}

restrição desse saber, uma vez que a produção do conhecimento passa a ser pertencente aos domínios do capital. (LUCENA, 2004, p. 208-209).

A indústria moderna repousa no instrumental de trabalho, na transferência da operação produtiva das mãos dos homens para as máquinas (máquina ferramenta), potencializando o grau de intensificação da força produtiva do trabalho. Marx (1978) discute em A Miséria da Filosofia que as relações sociais possuem sólidas ligações com as forças produtivas - a partir do momento em que os homens mudam a sua forma de produção, as relações sociais também são transformadas e o trabalho organiza-se e divide-se de acordo com os instrumentos de que dispõe. Para entendê-lo, inicia-se a análise pela sua divisão, dando ênfase à ascensão das máquinas:

\begin{abstract}
Não possuindo as condições materiais do trabalho, os trabalhadores são obrigados a venderem a sua força de trabalho em diferentes atividades, tornando-os indiferentes ao que produzem. A produção capitalista, que possui uma base revolucionária, através da Ciência, reorganiza sistematicamente a produção e o trabalho a ela submetido. Com efeito, na busca de domínio do mercado, o capital se desdobra de ramo em ramo da produção, obrigando o trabalhador a acompanhar o seu movimento, inventando e reinventando profissões. (MARX, 1978 apud LUCENA, 2004, p. 35).
\end{abstract}

A formação parcelar dos trabalhadores expressa em uma forma produtiva em que se divide o trabalho manual e intelectual potencializa o sentido do REUNI e, se compreende a argumentação de Marx de que não existem ideias simplesmente falsas da realidade, mas uma realidade falseada, invertida, que provoca a representação ideológica correspondente, ou seja, uma teoria materialista da falsa consciência, que em síntese, em seu desenvolvimento mais complexo da teoria é teoria da reificação (coisificação).

Os pressupostos epistêmicos marxianos, fugindo a qualquer anacronismo em termos comparativos, oferecem fundamentos para a interpretação da situação dos professores, suas condições de ensino e suas relações com o mundo do trabalho. As metas propostas nas empresas passam a ser exigidas dos próprios professores, intensificando e ocupando o seu tempo livre com o tempo do trabalho, aquilo que Marx em análise da manufatura, denominou de trabalho se confundir com o lar. Isso se traduz na adoção de novas tecnologias na educação que ocupa o espaço de trabalho do professor, independentemente de estar ou não nas unidades educativas. O festival de e-mails com suas propostas, cobranças $\mathrm{e}$ possibilidades, invade a vida dos professores, intensificando o estranhamento do e pelo trabalho:

Assim, seu rol de atividades é extenso e sua carga de trabalho se estende para além dos muros das instituições, da carga horária de oito horas diárias, da semana de cinco dias, com a produção de diversos tipos de doenças, desânimo, cansaço, ansiedade, visto que em cada trabalhador, conforme graus diferenciados, sempre existem limitações corporais e subjetivas no enfrentamento desse ritmo de trabalho. Com a reforma proposta, deve-se acrescentar a esse quadro, o sobretrabalho que poderá advir da multiplicação de estudantes sob sua responsabilidade, bem como o desgaste de um cotidiano sem sentido, pois 


\section{Revista HIISTEYIDIR On-line}

marcado pelo insucesso de estudantes que aprendem mal e competem pelo acesso ao $2^{\circ}$ nível. (LÉDA; MANCEBO, 2009, p. 58).

A precarização do trabalho dos professores com o REUNI apresenta-se em sua própria lógica constitutiva. Em análise à Portaria Interministerial MEC/MPOG n. 22, de 30 abril de 2007, Léda e Mancebo (2009, p. 59-60) entendem que tal documento possibilita a instauração de um "[...] banco de professores equivalentes", bem como a contratação de professores substitutos, a partir da criação de metas para a expansão do REUNI e seus limites orçamentários:

Em síntese, o banco de professores-equivalente corresponde ao total de professores de $3^{\circ}$ grau efetivos e substitutos em exercício na universidade, no dia 31 de dezembro de 2006, expresso na "unidade professor-equivalente". Para chegar a essa unidade, a Portaria toma como referência a equivalência salarial entre um professor efetivo e um professor substituto, atribuindo um fator (peso) diferenciado a cada docente segundo sua condição de trabalho. Assim, um docente adjunto, em dedicação exclusiva, por exemplo, vale um pouco mais $(1,55)$ que três professores efetivos em regime de $20 \mathrm{~h}(0,5)$ e um pouco menos do que quatro professores substitutos com $20 \mathrm{~h}(0,4)$ e tais fatores deverão ser considerados por ocasião da contratação de professores substitutos. $O$ governo avalia a institucionalização do 'banco' como um grande avanço do ponto de vista da gestão da universidade pública e admite a possibilidade de estendê-lo a outros setores da administração pública. Todavia, mesmo com as modificações introduzidas na Portaria Interministerial n. 224, de 23 de julho de 2007, considerando no cálculo a pós-graduação, o banco de professores equivalentes permanece um mecanismo ágil que força um aumento de produtividade institucional, em detrimento da qualidade, necessariamente, resultando na precarização das condições de trabalho.

O que se verifica é um processo que intensifica o trabalho de todos os professores nas IFES, no qual a precarização das condições de trabalho manifestas pelo REUNI possuem potencial de transformá-las em instituições apenas de ensino, e de baixa qualidade, reservando a pesquisa a centros de excelência financiados pelo capital. Aqui se materializa um processo por meio do qual alguns setores científicos são privilegiados, em detrimento de outros.

Isso se explica a partir da lógica do trabalho expressa no modo de produção capitalista. Tomando-se como referência o controle da burguesia sob a abstratividade do trabalho, o controle da Ciência e seus resultados são entendidos como um processo classista. O que produzir e como produzir passa a ser uma decisão das frações de classe burguesas, potencializando a divisão internacional do trabalho. O que se percebe é que o REUNI representa um modelo educacional oferecido aos trabalhadores e, consequentemente, em sua maioria, aos filhos dos pobres.

No capitalismo, as tecnologias que circulam o planeta não são homogêneas e de última geração. Os países de terceiro mundo têm acesso a tecnologias obsoletas, ou semiobsoletas, já abandonadas pelas nações que possuem uma posição predominante na divisão 
internacional do trabalho. Esse movimento se explica por intermédio de um processo complexo, dialético e contraditório entre a produção e a circulação das mercadorias.

A educação precarizada expressa no REUNI atende à própria posição do Brasil na Divisão Internacional do Trabalho, negando qualquer dimensão redentora da educação como ponto de partida de uma sociedade. Entendemos que a educação que aqui se apresenta é desdobramento das condições materiais produtivas expressas no modo de produção capitalista.

Como bem alertou Einstein (apud MÉSZÁROS, 2004, p. 288): “[...] por que a ciência aplicada, que é tão magnífica, economiza trabalho e torna a vida mais fácil, nos proporciona tão pouca felicidade? A resposta é simples: ainda não aprendemos a utilizá-la adequadamente."

\section{CONSIDERAÇÕES FINAIS}

O estudo sobre os governos FHC e Lula trouxe fundamentos para a interpretação da breve e conturbada história da influência do Neoliberalismo no Brasil. Partindo do entendimento marxiano por meio do qual o particular se explica no geral, percebemos que o processo em curso no Brasil ocorre conforme amplas mudanças e contradições que ora se desenvolvem até mesmo internacionalmente.

O leitor deve perceber que na última frase utilizamos a conjugação verbal no tempo presente. Isso não se deu ao acaso. Em outras palavras, o governo Dilma, tema que aqui não tratamos, continua as ações políticas expressas por FHC e Lula, não rompendo com as tramas do mercado internacional e seu ávido interesse em garantir as formas reprodutivas e cumulativas do capital.

Marx apontou no Livro 3 de $O$ Capital a tendência da configuração de crises cíclicas no capitalismo expressas em intervalos cada vez menores de tempo. A sua afirmação de o apogeu anunciar a catástrofe e a catástrofe, o apogeu, norteia o entendimento sobre os rumos da sociedade capitalista. A dimensão bancária expressa na financeirização do capital em forma mundializada norteou e norteia grupos financeiros ávidos pelo enriquecimento, independentemente do custo social que essa ação signifique.

O capital possui uma forma expansiva incontrolável. Sua ação de expansão e consumo espalha-se por todo o planeta, cobrindo todas as formas produtivas possíveis. A expansão incontrolável do capital, tese formidável defendida por Marx e retomada por Mészáros, causa impacto provocando mudanças e reestruturações em nível internacional, acompanhadas de ideologias que justifiquem esse fim.

As crises cíclicas do capital, construções humanas e não sobrenaturais, foram justificadas pelas frações burguesas de classe como um fenômeno natural e conjuntural 
intrínseco ao movimento do mercado, como uma força metafísica presente além da própria vontade do homem. A tese da economia política liberal constituída pela centralidade do mercado se manifesta na relação de a circulação preceder a produção ganhou ênfase no cenário do capitalismo nos últimos quarenta anos. O entendimento da circulação como ponto de partida de uma sociedade omite as relações de exploração de classe que se desenvolvem em âmbito local, regional, nacional e internacional. As relações entendidas como desprovidas da existência de classes em conflito e disputa são entendidas como um fenômeno de indivíduos relacionando-se com indivíduos, produtores com consumidores e vice-versa.

Por outro lado, rechaçamos os pressupostos da economia política tão caros a Adam Smith e seus seguidores. Isto porque entendemos que o processo econômico, político e social presente nos governos FHC e Lula manifesta relações classistas expressas em uma intensificação da reprodução do capital em sua forma financeira, que termina atendendo aos trâmites sociais inerentes às respostas à crise do Welfare State exposta pela queda do Sistema de Bretton Woods e pelos dois choques do petróleo.

O processo de reestruturação que ocorreu entre as décadas de 60 a 80, século XX, implicou no empobrecimento dos países periféricos, acompanhado da ávida busca dos países centrais e dos setores transnacionais a eles vinculados, em garantir o retorno dos seus investimentos, criando um mercado cativo para o empréstimo constante de capital. O Brasil participou de forma subordinada nesse movimento internacional. Em que pese os "bravejos" de Collor, a autossuficiência de FHC e a linguagem "neo-populista" de Lula, a condição do país é subordinada em termos das relações econômicas e políticas com os países centrais. A negociação internacional com o FMI em termos das formas de pagamento do montante e juros da dívida externa brasileira confirma essa afirmação.

O Plano Real foi uma invenção do Plano Brady. Em outras palavras, levando em consideração a necessidade expansiva do capital mundializado, com a crise do capitalismo no final do século passado, a própria forma de regulação estatal se transformou. A expansão do capital em sua forma financeira e produtiva implicou na mudança da ação do Estado Nacional, que deveria abrir todos os espaços possíveis para uma internacionalização de suas próprias economias.

O Plano Real foi expressão maior dessa afirmativa. O que se percebe foi uma aposta internacional em governos de longa duração para viabilizar as medidas econômicas necessárias aos interesses anteriormente demonstrados. As metas que um governo não conseguisse cumprir seriam realizadas pelo governo seguinte, sustentado por sua própria legitimidade eleitoral. Esse foi o sentido demonstrado daquilo que FHC não conseguiu cumprir e Lula terminou, merecendo destaque a mudança na Previdência Social, a discussão dos transgênicos, dentre outros. 
As ações educacionais nesses dois governos foram implacáveis e legitimadas pelo mesmo princípio neoliberal. Tomando como referência o ensino superior, o governo FHC investiu em políticas públicas voltadas à expansão das instituições privadas. Ocorreu o crescimento e expansão destas instituições em todo o território nacional, algumas com considerável condição de ensino e, a ampla maioria, em condições precárias de funcionamento.

Essa expansão justificou-se pelo discurso da individualidade e empregabilidade. Um processo de capacitação por conta própria ganhou corpo no Brasil, legitimado por um entendimento ideológico que a sociedade do desemprego que ali se apresentava era, na realidade, uma sociedade de oportunidades àqueles mais preparados para o mercado do trabalho. Reformas curriculares voltadas à redução do tempo formativo foram criadas, sacrificando as disciplinas de cunho social, científico e filosófico dos conteúdos oferecidos aos acadêmicos.

A expansão do ensino superior no governo FHC foi um processo contraditório. Por um lado, instaurou a precariedade na oferta das condições de ensino na maior parte das instituições privadas de ensino superior no Brasil, por outro lado, abriu espaço de trabalho para jovens professores. A dificuldade para as condições de oferta do ensino foram acompanhadas e exigidas pela organização do movimento social, de no mínimo exigir que $30 \%$ de mestres e/ou doutores, por curso, compusessem os quadros docentes das IES. Ratifica-se que a referida conquista é, sem dúvida, fruto de luta histórica das organizações docentes dos professores, merecendo destaque o ANDES-SN.

Por sua vez, a expansão no governo Lula não rompeu com os pressupostos ideológicos da empregabilidade manifestos no governo FHC. A mudança legislativa em torno dos 30\% de professores titulados por curso para 30\% do montante de uma instituição proporcionou a demissão em massa de professores titulados de Instituições Privadas de Ensino Superior no Brasil, chegando ao ponto de professores esconderem a titulação com medo da perda do emprego.

A expansão universitária do governo Lula ocorreu com o REUNI. Ele expressou um movimento de expansão precária sustentado pelo mesmo princípio da empregabilidade proposta no governo FHC. A discussão do REUNI foi acompanhada pela tentativa de instauração de centros de excelência, onde ocorreriam os maiores investimentos em Ciência e Tecnologia. Essa afirmação manifesta a contradição, por meio da qual a precariedade das condições oferecidas pelas IFES aos filhos dos pobres seria acompanhada pela formação de centros de excelência em total consonância aos interesses do capital. Esta foi uma iniciativa voltada ao interesse de o Estado financiar a iniciativa privada, desenvolvendo patentes e oferecendo bolsas a pesquisadores, sendo que o resultado de suas pesquisas seria automaticamente absorvido pela iniciativa privada. 
Essa ação implicou na divisão entre os próprios professores que, acometidos pelo conceito da eficiência, negam aos outros e a si mesmos, potencializando o crescimento da alienação e do estranhamento do e pelo trabalho. O projeto neoliberal abriu espaços de trabalho a centenas de professores, mas, ao mesmo tempo, intensificou a precarização de suas próprias condições para o exercício do magistério. O projeto neoliberal, por representar a materialização da exploração de classe pela burguesia, produziu tentáculos em todos os segmentos dos países periféricos, merecendo destaque o Brasil.

A precarização do trabalho docente materializado pelo REUNI nas IFES não é um caminho sem volta. O caminho passa pela resistência política e sindical dos professores nele inseridos. Em que pese a condição lamentável de trabalho da maioria dos profissionais no exercício do magistério, são essas as condições materiais para a construção das futuras lutas sindicais, agora com um maior conjunto de professores, sendo o ANDES-SN um importante interlocutor no futuro.

Por fim, diante de toda essa contextualização, acredita-se na afirmativa de Marx (1978, p. 6) de que "[...] os homens fazem a sua história, mas não a fazem como querem; não a fazem sob circunstâncias de sua escolha e sim, sob aquelas que se defrontam diretamente, legadas e transmitidas pelo passado".

\section{REFERÊNCIAS}

ANDES, Cadernos. Concepções de universidade no contexto do PDE: universidades de ensino X universidades de pesquisa. Brasília, n. 25, p. 1-41, ago. 2007.

ANDRIOLI, A. I.; SCHMALZ, S. O governo Lula: continuidade da política neoliberal no Brasil? Revista Espaço Acadêmico. n. 62, jul. 2006. Disponível em: <http://www.espacoacademico.com.br/062/62andrioli.htm〉. Acesso em: 25 abr. 2012.

BRASIL. Decreto n. 6.096, de 24 de abril de 2007. Institui o programa de apoio a planos de reestruturação e expansão das universidades federais - REUNI. Brasília: Casa Civil. Disponível em: <http://www.planalto.gov.br/ccivil_03/_ato2007-

2010/2007/decreto/d6096.htm>. Acesso em: 2 ago. 2012.

BRESSER-PEREIRA, L. C. O modelo estrutural de gerência pública. Revista de Administração Pública, v. 42, n. 2, mar./abr. 2008.

BRESSER-PEREIRA, L. C. O novo desenvolvimentismo e a ortodoxia convencional. São Paulo em Perspectiva, v. 20, n. 3, p. 5-24, jul./set. 2006.

BRESSER-PEREIRA, L. C. O paradoxo da esquerda no Brasil. nov. 2005. Disponível em:

<http://www.filolite.com/extranet_filolite/content/arquivos_pdf/dedde912ffe64a9b92774cc 6d2ef04aa.pdfBrasil>. Acesso em: 12 mar. 2012. 
Artigo

doi: $10.20396 /$ rho.v18i1.8645868

DUARTE, N. Sociedade do conhecimento ou sociedade das ilusões? Quatro ensaios crítico-dialéticos em filosofia da educação. Campinas: Autores Associados, 2003.

GOMES, W. Transformações da política na era da comunicação de massa. São Paulo: Paulus, 2004.

LÉDA, D. B.; MANCEBO, D. REUNI: heteronomia e precarização da Universidade e do trabalho docente. Revista Educação e Realidade, n. 34, 2009.

LIMA, K. Contra-reforma da educação nas universidades federais: o REUNI na UFF, 2009. Disponível em: <http://www.aduff.org.br/especiais/download/20090917_contrareforma.pdf $>$. Acesso em: 1 set. 2014.

LIMA, K. Contra-reforma da educação superior em FHC e Lula. São Paulo: Xamã, 2007.

LUCENA, C. Portal Trabalho Educação e Sociedade. Disponível em: < https://portaltrabalho.wordpress.com/producao-cientifica/artigos-cientificos>. Acesso em: 5 maio 2013.

LUCENA, C. Tempos de destruição: educação, trabalho e indústria do petróleo no Brasil. Campinas: Autores Associados; Uberlândia: Ed. da EdUFU, 2004.

MARQUES, A. P. B.; PEREIRA, V. P. Nem esquerdas e nem revolução, o processo de busca do centro. Revista Ágora, Vitória, n. 1, 2005.

MARX, K. 18 Brumário de Luís Bonaparte. Rio de Janeiro: Paz e Terra, 1978.

MARX, K. O Capital: crítica da economia política. Tradução Regis. Barbosa e Flávio R. Kothe. 3. ed. São Paulo: Nova Cultural, 1988. Livro 1, v. 12.

MELO, A. Avaliação institucional do ensino superior: controle e condução de política educacional, científica e tecnológica. In: NEVES, L. M. W.; SIQUEIRA, Â. (Org.). Educação superior: uma reforma em processo. São Paulo: Xamã, 2006. p. 125-146.

MERCADANTE, A. As bases do novo desenvolvimentismo no Brasil: análise do governo Lula entre 2003 e 2010. 2010. Tese (Doutorado em Economia) - Instituto de Economia, Universidade Estadual de Campinas, Campinas, 2010.

MÉSZÁROS, I. O poder da ideologia. São Paulo: Boitempo, 2004.

NEVES, L. M. W. (Org.). Reforma Universitária do governo Lula: reflexões para o debate. São Paulo: Xamã, 2004.

NEVES, L. M. W.; SIQUEIRA, Â. Educação superior: uma reforma em processo. São Paulo: Xamã, 2006. 
ROSA, R. Ensino superior: a reforma ditada pela União Européia. 2003. Disponível em: <http://resistir.info/rui/educacao_ameacada_5.html>. Acesso em: 28 jan. 2013.

SILVA JÚNIOR, J. dos. R.; SGUISSARDI, V. Novas faces da educação superior no Brasil. Reformas do estado e mudanças na produção. Bragança Paulista: Ed. da EDUSF, 1999.

VAISMAN, E. A obra de juventude e da maturidade: ruptura ou continuidade? In: BOITO JÚNIOR, A. et al. (Org.). A obra teórica de Marx: atualidade, problemas e interpretações. São Paulo: Xamã, 2000. p. 13-23. v. 1.

Notas

${ }^{1}$ Artigo extraído da Tese de Doutorado em Educação Os governos FHC e Lula e a ressignificação do neodesenvolvimentismo: o REUNI, defendida no Programa de Pós-Graduação em Educação defendida no Programa de Pós-Graduação em Educação da Universidade Federal de Uberlândia (PPGED/UFU).

${ }^{2}$ Doutora em Educação pelo Programa de Doutorado Interinstitucional (DINTER) UFU/UNIFAP. Mestre em Desenvolvimento Regional - UNIFAP. Graduada em Economia - UNAMA e em Pedagogia - UEPA. Professora Adjunto/ Curso de Pedagogia, matéria Didática - UNIFAP. Secretária Municipal de Educação (2013-2015) - Macapá/AP. E-mail: antoniaunifap@gmail.com.

${ }^{3}$ Doutor em Filosofia e História da Educação - UNICAMP. Pós-Doutor em Educação - UFSCar. Cientista Social pela - PUC/Campinas. Mestre em Educação - PUC/Campinas. Bolsista de Produtividade em Pesquisa 2/CNPq. Pesquisador do Histedbr. Professor Associado III/ Faculdade de Educação - UFU. E-mail: lucenabonsais@gmail.com.

${ }^{4}$ Doutora em Educação pela Universidade Federal do Pará UFPa. Mestre em Desenvolvimento Regional UNIFAP. Graduada em Pedagogia - UNIFAP. Professora Adjunto/Curso de Pedagogia, matéria Política em Educação - UNIFAP.

${ }^{5}$ Ministros Pedro Malan, Fernando Henrique Cardoso, Henrique de Campos, Antônio Palocci e Ricardo Berzoini.

Submetido em: 30/04/2016

Aprovado em: 23/01/2018

Publicado em: 16/04/2018 